\title{
Premonitory symptoms of stroke in evolution to the locked-in state
}

\author{
JOHN LIU, STANLEY TUHRIM, ${ }^{*}$ JESSE WEINBERGER, ${ }^{*}$ SUN K. SONG, $\ddagger$ PAUL J \\ ANDERSON $\dagger$
}

From the Department of Neurology* and Division of Neuropathology $\dagger$ The Mount Sinai School of Medicine, City University of New York, and the Division of Neuropathology, City Hospital Centre at Elmhurst $\ddagger$, New York, USA

SUMMARY Three patients, who subsequently developed the locked-in state characterised by quadriplegia and mutism with an alert sensorium, initially had mild dysarthria and uncrossed hemisensory or hemimotor deficits involving the face and ipsilateral extremities. Case one initially mimicked a left cerebral lesion with right hemisensory deficits, a mild right facial paresis and a right homonymous field deficit. Case two initially developed both left hemimotor and hemisensory deficits and later developed a paresis of right conjugate gaze. Case three presented with left hemimotor deficit, and mild paresis of conjugate gaze to the right. All three patients died. Rostral brainstem infarctions were found at necropsy in cases one and two. Case three had a radiolucent area of the brainstem demonstrated by CT Scan. Hemisensory and hemimotor deficits also have been noted to precede reported cases of pontine infarction with the locked-in state. Acute onset of uncrossed hemisensory and hemimotor deficits with dysarthria may be caused by infarction of the pons which may predispose to the locked-in state.

The locked-in state is a devastating neurological syndrome secondary to infarction or hemorrhage in the ventral and rostral pons (-15). Patients are unable to move their extremities or speak, but are alert and responsive. They communicate with vertical eye movements and lid movements. Horizontal eye movements usually are impaired. The locked-in state can occur acutely, but often premonitory symptoms are present.

We report three cases of patients who presented with mild neurological deficits preceding the development of the locked-in state. All three initially had dysarthria and a mild uncrossed hemisensory or hemimotor deficit involving face and extremities on the same side. They were all felt to have had a mild cerebral or brainstem vascular accident, until the locked-in state evolved. Post-mortem examination was obtained in two patients. In one, a large infarction of the rostral pons at the mesencephalic junction was identified. In the second, a smal-

Address for reprint requests: Dr Jesse Weinberger, The Mount Sinai School of Medicine, 1 Gustave Levy Place, New York, New York 10029, USA

Received 3 July 1982 and in revised form 29 October 1982 Accepted 13 November 1982 ler infarction in the midventral pons was found. Both had infarctions involving the pyramidal tract above the facial nucleus. This accounted for the initial symptomatology involving the face and limbs on the same side. In the third case, a brainstem lesion was revealed by computed tomography (CT).

These cases illustrate that patients presenting with symptoms of dysarthria and uncrossed hemisensory or hemimotor deficits may have ischaemic lesions in the ventral or rostral pons which may progress to the locked-in state.

\section{Case reports}

Case 1 A 75-year-old diabetic, hypertensive woman was admitted with slurred speech, dizziness and unsteadiness of gait of one day's duration. She had noted circumoral numbness a few days earlier. She denied diplopia, vomiting, prior weakness or sensory loss. Medications were tolbutamide and methyldopa. The blood pressure was 200/100 $\mathrm{mmHg}$ and pulse was $69 /$ minute. She was alert, oriented and named objects well. Speech was dysarthric. There was a right homonymous hemianopia but objects could be located in the affected field. Pupils were equal and reactive. Fundi were normal. 
Ocular movements were normal. There was a mild right facial paresis with drooling from the right corner of the mouth. The right palpebral fissure was wider than the left. Right facial sensation was diminished to light touch. Strength was unimpaired bilaterally and reflexes were symmetrically active with flexor plantar responses. Vibration and light touch sensation were impaired on the right side. Pin-prick and position perception were normal. Rapid alternating movements were slightly impaired bilaterally, more on the right. The heel to knee to shin manoeuvre was clumsy on the right. She walked with an unsteady shuffling gait. Spinal fluid, blood chemistries, haematocrit and sedimentation rate were normal.

Twelve hours later, she was found to be unresponsive with Cheyne-Stokes respirations. Blood pressure was $200 / 90 \mathrm{mmHg}$ and pulse was $60 / \mathrm{min}$. Eyes were deviated downward without response to oculocephalic manoeuvre or to cold water caloric testing. Pupils were $1.5 \mathrm{~mm}$ bilaterally and minimally reactive to light. Corneal responses were depressed bilaterally. There was a quadraparesis with slight extensor posturing of the upper extremities to noxious stimuli. Reflexes were $3+$ bilaterally with bilateral extensor plantar responses. She was placed on a respirator. Computed tomography revealed a left sided pontine lucency. Two days later, the patient had upper facial grimacing with crying when spoken to by her sister. Pupils were at 2 $\mathrm{mm}$ and reactive to light. Resting gaze was disconjugate with slight right eye adduction. The patient looked down and upward to the midline from a down position upon command. Gaze above the midline was impaired. She had no horizontal eye movements on passive head turning or ice water caloric testing. Opticokinetic response to a striped drum was absent in all directions. Corneal reflexes were present bilaterally. She could not raise her eyebrows or forcefully close her eyelids to command. She was quadraparetic with extensor posturing of the arms and slight withdrawal of the lower extremities to painful stimuli. She developed a fever and died three weeks later.

Necropsy disclosed severe atherosclerosis involving aortic, renal iliac, coronary and carotid arteries. There was bilateral bronchopneumonia of recent origin. Examination of the brain disclosed severe atherosclerotic plaque formation within the vertebral and basilar arteries. Multiple cross-sections through these vessels disclosed varying degrees of narrowing of the lumen, most pronounced in the mid-portion of the basilar artery overlying the base of the pons. Dissection of the cerebrum disclosed a well circumscribed old infarct in the head and body of the right caudate nucleus, measuring $0.5 \mathrm{~cm}$ in maximal diameter. There were bilateral, wedgeshaped recent infarcts of the medial and ventral surfaces of the occipital lobes, each measuring 3 to $4 \mathrm{~cm}$ in maximal extent. Examination of the brain stem disclosed extensive recent infarction of the crus cerebri and tegmentum and base of pons bilaterally (fig 1). Within the pons, the zone of infarction measured $2.5 \mathrm{~cm}$ rostrocaudally, $2.0 \mathrm{~cm}$ transversely, and $1.5 \mathrm{~cm}$ dorsoventrally.

Microscopic examination disclosed multiple recent infarcts in the calcarine cortex of both occipital lobes. Focal infarcts were also present in the thalamus. The most extensive zone of infarction involved most of the base of the rostral and midportions of the pons. At the level of the middle cerebellar peduncle, the infarction extended dorsally to destroy most of the pontine tegmentum. Rostrally, the infarct extended into both crus cerebri where extensive portions of the substantia nigra and fiber tracts of the crus were destroyed. Recent focal infarcts were also present in the central white matter of the cerebellum. The medulla contained irregular zones of rarefaction and there was descending degeneration in both corticospinal tracts. Swollen axonal fragments and reactive hyperplastic astrocytes were observed in the medullary pyramids and the lateral funiculi of the cervical spinal cord. Sections of the basilar artery showed severe atherosclerotic narrowing of the lumen, but no areas of occlusion were found. All of the above described infarcts were of similar recent age, while the focal infarct in the right caudate nucleus was considerably older.

The neuropathological diagnoses were: (1) infarct, recent, extensive, of pons, mid-brain, cerebellum, thalamus, and occipital lobes bilaterally, (2) descending degeneration, recent, of corticospinal tracts, (3) infarct, old, focal, right caudate nucleus, (4) atherosclerosis, severe, basilar artery.

Case 2 A 67-year-old white male complained of three days of pain in his left ear and episodic unsteadiness of increasing frequency lasting approximately fifteen minutes. He also complained of episodes of numbness and tingling of the left arm and face associated with slurred speech. Initial neurologic examination was unremarkable. Upon awakening seven days after onset of symptoms, the patient was noted to have slurred speech, a right conjugate gaze paresis, left central facial nerve palsy and a mild left hemiparesis. The patient reported decreased sensation to pinprick over the entire left side of the body, including the face. Position sense was preserved. Over the next twenty-four hours the patient became quadriplegic with bilateral extensor posturing and bilateral extensor plantar responses, 


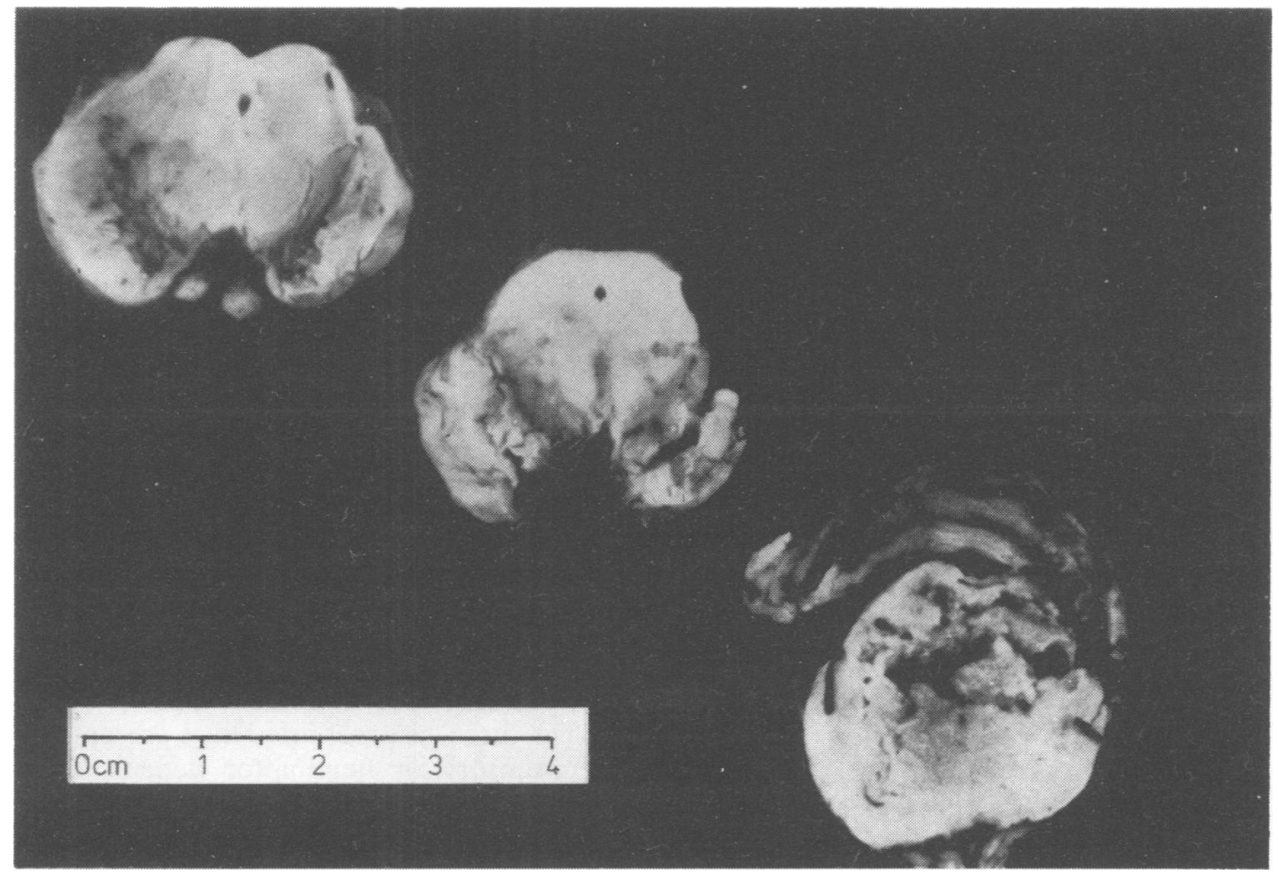

Fig 1 Case 1. Transverse sections through mid and caudal levels of midbrain (upper left and centre) and rostral level of pons (lower right). Extensive recent infarct destroys most of the tegmentum and base of the pons and extends rostrally to destroy portions of the crus cerebri.

but he remained responsive to verbal stimuli. Examination of the cerebrospinal fluid was within normal limits. A CT scan without contrast performed a week later revealed no abnormality. Subsequently the patient regained some motion of the right upper and lower extremities and was able to follow commands with his eyes but could not speak. He developed pneumonia and died two weeks after the initial event.

Necropsy disclosed generalised atherosclerosis with an old healed myocardial infarct on the left lateral wall. There was bilateral bronchopneumonia with pleural effusion and pulmonary emphysema. The brain showed moderate to severe atherosclerotic plaque formation within the veretebral and basilar arteries. Cross sections through these vessels revealed varying degrees of narrowing of the lumen, but no areas of occlusion. Dissection of the cerebral hemispheres disclosed no abnormalities. Examination of the brain stem showed well circumscribed focal areas of old infarction in the ventral aspect of the base of the mid and lower pons. The largest measured $0.8 \mathrm{~cm} \times 0.8 \mathrm{~cm} \times 0.7 \mathrm{~cm}$ and was situated along the ventral margin of the pons at the level of the trigeminal nuclei. Two smaller infacts were present in the left basis pontis in the area of the left corticospinal tract.
Numerous histological sections through the brainstem showed that the infarcts were all of recent onset (compatible with the terminal two week history). The infarcts were well circumscribed and were limited to the basis pontis where the principal structures destroyed were the ventral and adjacent portions of the medial pontine decussation (decussatio ventralis pontis) and the stratum superficiale of the pontine base (fig 2). The ventral nucleus of the pons (nucleus ventralis pontis) and descending cerebellopontine fibers were also affected. A smaller, separate infarct destroyed medial portions of the left corticospinal tract and the frontopontine tract. Adjacent portions of the stratum profundum pontis were also involved on the left side. Sections of the basilar and vertebral arteries showed severe atherosclerosis with varying degrees of lumenal narrowing; no occlusions were encountered.

The neuropathological diagnoses were. (1) infarct, recent, focal, of the pons (basis pontis), bilateral, (2) atherosclerosis, severe, basilar and vertebral arteries.

Case 3 A 76-year-old black female with a past history of hypertension and atherosclerotic heart disease was admitted to the hospital after she awakened from a nap and found that she was 


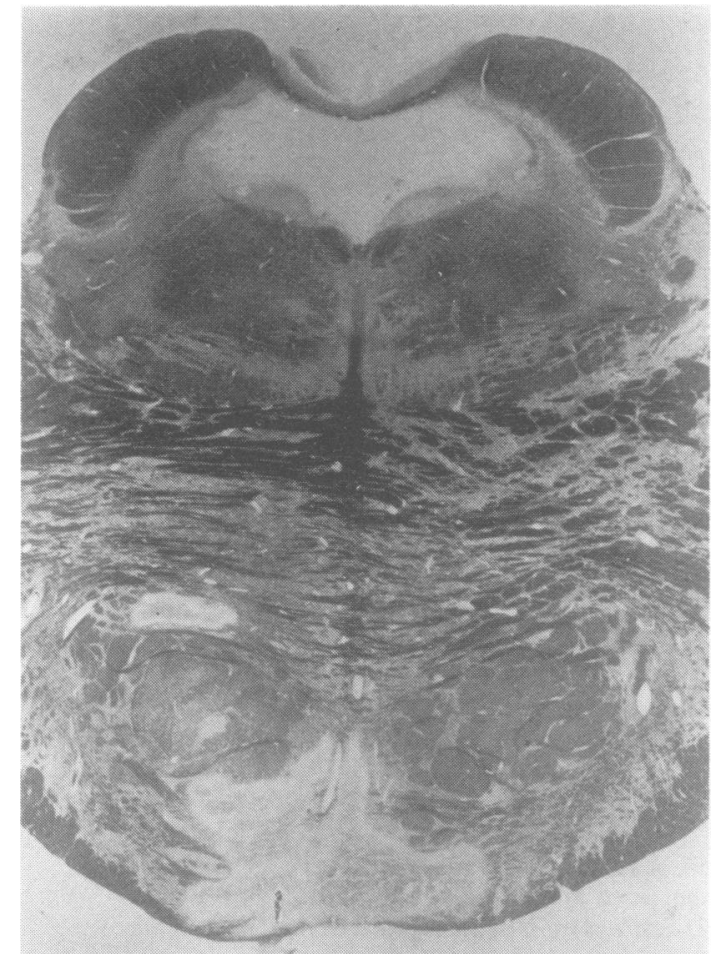

Fig 2 Case 2. Section through the pons at the level of the trigeminal nuclei. Recent infarction destroys the ventral and medial pontine decussation and the stratum superficiale of the pontine base. Smaller infarcts are present in the left corticospinal tract and the stratum profundum pontis (Kluver stain, $\times 3$ ).

unsteady on her feet. Examination on admission revealed a normal mental status. Her speech was dysarthric. She had a left gaze preference but could look to her right. Her pupils were $2 \mathrm{~mm}$ in diameter and normally reactive. There was decreased optokinetic nystagmus to the left. Her tongue deviated to the left on protrusion and there was a left central facial nerve palsy. There was a left hemiparesis more marked in the upper extremity and greater distally than proximally with a total paralysis of the left hand. Sensory testing revealed no abnormalities. Deep tendon reflexes were increased on the left and there was a right extensor plantar response. Six hours later, she was found to be obtunded and was observed to have a paralysis of conjugate gaze to the right and continuous extensor posturing. She was treated with $16 \mathrm{mg}$ dexamethasone qd. The following morning she was quadraplegic, unable to speak but able to follow commands with vertical eye movements. The eyes were deviated to the left, but could still move to the right. A CT scan performed without contrast enhancement revealed an area of decreased density in the brainstem compatible with an infarction. The patient eventually succumbed to pneumonia. No necropsy was performed.

\section{Discussion}

The locked-in state may develop from infarction in the rostral and ventral pons secondary to thrombosis or occlusion of the basilar artery. ${ }^{1-15}$. The prognosis is poor, with 31 of 34 reported cases dying within a few weeks of onset. Three patients survived for over two years. ${ }^{413}$ Review of the clinical presentation in 28 necropsy cases revealed that 25 were due to ischaemic vascular disease. Eleven patients developed the locked-in state acutely while 14 had premonitory symptoms of brain stem infarction. Eleven of these 14 patients had hemisensory or hemimotor deficits as part of their preliminary symptoms. (table).

The three cases reported here presented with mild hemisensory or hemimotor deficits involving the ipsilateral face and extremities. They were initially felt to have cerebral infarctions, but the finding of dysarthria suggested a brainstem localisation. All three had symptoms similar to those described with "lacunar" infarcts such as pure motor hemiparesis ${ }^{16}$ or pure hemisensory deficit. ${ }^{17}$ Three of nine necropsied cases described by Fisher and Curry with pure motor hemiparesis had concomitant dysarthria and were found to have pontine infarcts. ${ }^{16}$ Two of the three had rapid progression and died shortly after onset. The patients with cerebral lesions had no dysarthria, and recovered from their neurologic deficits, but succumbed to other causes.

Strokes in the vertebrobasilar circulation may have a good prognosis, with full recovery occurring in $55 \%$ of cases whose symptoms persist for at least 2 weeks. ${ }^{18}$ Patients with severe hemimotor deficits have a poorer prognosis. ${ }^{19}$ This deterioration may be more predominant when the lesion produces a contralateral hemimotor or hemisensory deficit involving the face on the same side as the extremities. These lesions may be difficult to discriminate from cerebral infarcts, especially when there is a homonymous hemianopsia due to compromise of flow in the posterior cerebral circulation, as in Case 1. A pontine lesion may be indicated when there is concurrent dysarthria or paresis of conjugate gaze with the eyes deviated towards the paresis.

It is important to recognise that brainstem infarction with symptoms and signs referrable to the rostral pons may lead to more severe deficits. Since most infarctions in this region are secondary to thrombotic occlusive disease of the basilar artery 
Table Presenting symptoms and anatomical pathology of the locked-in state

\begin{tabular}{|c|c|c|c|c|}
\hline Presenting symptom & Number & Reference & Anatomic pathology & Vascular Pathology \\
\hline $\begin{array}{l}\text { Hemiparesis including ipsilateral face } \\
\text { Hemiparesis with dysarthria }\end{array}$ & $\begin{array}{l}2 \\
2 \\
1 \\
1\end{array}$ & $\begin{array}{l}(1,2) \\
3) \\
4) \\
\text { Case } 3\end{array}$ & $\begin{array}{l}\text { Ventral pontine infarct } \\
\text { Ventral pontine infarct } \\
\text { Ventral pontine infarct } \\
\text { Pontine infarct on CT }\end{array}$ & $\begin{array}{l}\text { Basilar occlusion } \\
\text { Basilar occlusion } \\
\text { Vertebral occlusion } \\
\end{array}$ \\
\hline Hemiparesis with dysarthria and ataxia & 1 & $(5)$ & $\begin{array}{l}\text { Infarct pons, cerebral } \\
\text { peduncle }\end{array}$ & $\overline{\text { Basilar occlusion }}$ \\
\hline Hemiparesis with diplopia and dysarthria & 1 & (6) & $\begin{array}{l}\text { Infarct pons, midbrain } \\
\text { medulla }\end{array}$ & Basilar occlusion \\
\hline Hemisensory syndrome with dysarthria & $\begin{array}{l}2 \\
1\end{array}$ & $\begin{array}{l}\text { Case } 1 \& 2 \\
(3)\end{array}$ & $\begin{array}{l}\text { Ventral pontine infarct } \\
\text { Ventral pontine infarct }\end{array}$ & $\begin{array}{l}\text { Basilar stenosis } \\
\text { Basilar occlusion }\end{array}$ \\
\hline Crossed sensory syndrome & 1 & (3) & Ventral pontine infarct & Basilar occlusion \\
\hline $\begin{array}{l}\text { Crossed motor syndrome with sensory } \\
\text { loss and dysarthria }\end{array}$ & 1 & (6) & $\begin{array}{l}\text { Infarct pons, midbrain, } \\
\text { medulla }\end{array}$ & $\begin{array}{l}\text { Thrombosis of fusiform } \\
\text { aneurysm basilar artery }\end{array}$ \\
\hline Truncal ataxia & 1 & (7) & $\begin{array}{l}\text { Infarct upper pons and } \\
\text { midbrain }\end{array}$ & Basilar occlusion \\
\hline Acute locked-in state & $\begin{array}{l}5 \\
1\end{array}$ & $(2,8-11)$ & $\begin{array}{l}\text { Ventral pontine infarct } \\
\text { Pontine infarct involving } \\
\text { Cerebral peduncles }\end{array}$ & $\begin{array}{l}\text { Basilar occlusion } \\
\text { Basilar occlusion }\end{array}$ \\
\hline No information & $\begin{array}{l}4 \\
2\end{array}$ & (4) & $\begin{array}{l}\text { Ventral pontine infarct } \\
\text { No post-mortem }\end{array}$ & $\begin{array}{l}\text { Basilar occlusion } \\
\text { Survived several years }\end{array}$ \\
\hline Post head trauma & 1 & (13) & No post-mortem & 2 year survival \\
\hline $\begin{array}{l}\text { Post surgical resection of } \\
\text { acoustic neuroma }\end{array}$ & $\begin{array}{l}1 \\
1\end{array}$ & (14) & Ventral pontine infarct & Basilar occlusion \\
\hline Progressive quadriparesis & 1 & (15) & Reticulum cell sarcoma, pons & \\
\hline
\end{tabular}

(table), anticoagulant therapy may be indicated in these patients when the initial deficit is mild. Anticoagulant therapy has been shown to be of some benefit in several controlled trials on patients with brainstem stroke in evolution. ${ }^{20}{ }^{21}$ It may prevent the occurrence of severe neurologic disorders such as the locked-in state in patients presenting with hemisensory or hemimotor findings and dysarthria if this is recognised as an ischaemic event in the contralateral rostral pons.

\section{References}

${ }^{1}$ Kubik CS, Adams RD. Occlusion of the basilar artery-a clinical and pathological study. Brain 1946;69:73-121.

${ }^{2}$ Dehaene I, Martin JJ. "Locked-In" syndrome a clinicopathological study of two cases. Eur Neurol 1976;14:81-9.

${ }^{3}$ Cravioto H, Silberman J, Feigin I. A clinical and pathological study of akinetic mutism. Neurology (Minneap) 1960;10:10-21.

4 Hawkes CH. "Locked-In" Syndrome. Report of seven cases. Br Med J 1974;4:379-82.

${ }^{5}$ Fang HC, Palmer JJ. Vascular phenomena involving brainstem structures. Neurology (Minneap) 1956;6:402-19.

' Nordgren RE, Markesby WR, Fukadi K, Reeves AG. Seven cases of cerebromedullospinal disconnection: the "Locked-In" syndrome. Neurology (Minneap) 1971;21:1140-8.
${ }^{7}$ Karp JS, Hurtig HI. "Locked-In" state with bilateral midbrain infarcts. Arch Neurol 1974;30:176-8.

${ }^{8}$ Halsey JH, Caballo SR, Crosby EC. The supranuclear control of voluntary lateral gaze. Neurology (Minneap) 1967;17:928-33.

9 Halsey JH, Downie AU. Decerebrate rigidity with preservation of consciousness. J Neurol Neurosurg Psychiatry 1966;29:350-5.

${ }^{10}$ Kemper TL, Romanul CA. State resembling akinetic mutism in basilar artery occlusion. Neurology (Minneap) 1967;17:74-80.

$"$ Chase TN, Moretti L, Prensky AL. Clinical and electroencephalographic manifestations of vascular lesions of the pons. Neurology (Minneap) 1968;18:357-658.

12 Plum F, Posner JB. The Diagnosis of Stupor and Coma. Ed 3. Philadelphia: FA Davis Co, 1980:159.

${ }^{13}$ Feldman MH. Physiological observations in a chronic case of "Locked-In" syndrome. Neurology (Minneap) 1971;21:478.

${ }^{14}$ Briemond $\mathrm{A}$. Thrombosis of the basilar artery and vascularization of the brainstem. Brain 1951;74:300-17.

${ }^{15}$ Cherington M, Stears J, Hodges J. Locked-In syndrome caused by a tumor. Neurology (Minneap) 1976;26:180-2.

${ }^{16}$ Fisher CM, Curry HB. Pure motor hemiplegia of vascular origin. Arch Neurol 1965;13:30-47.

${ }^{17}$ Fisher CM. Pure sensory stroke involving face, arm and leg. Neurology (Minneap) 1965;15:76-80.

${ }^{18}$ Vander Dritt JHA. Stroke with complete recovery in vertebrobasilar insufficiency. In: Meyer JS, Lechner H, Reivich M (eds). Cerebrovascular Disease. Amsterdam: Excerpta Medica, 1977:78-82.

19 Williams D. Wilson TG. The diagnosis of the major and minor syndromes of basilar insufficiency. Brain 1962;85:741-4. 
${ }^{20}$ Millikan CH, Siekert RG, Whisnant JP. Anticoagulant therapy in cerebral vascular disease-Current status. JAMA 1958;166:587-91.
${ }^{21}$ Fisher CM. The use of anticoagulants in cerebral thrombosis. Neurology (Minneap) 1958;8:311-32. 